\title{
Measurement of combined oximetry and cutaneous capnography during flexible bronchoscopy
}

\author{
P.N. Chhajed, R. Rajasekaran, B. Kaegi, T.P. Chhajed, E. Pflimlin, \\ J. Leuppi and M. Tamm
}

ABSTRACT: The aim of the present study was to assess the feasibility of measuring combined arterial oxygen saturation measured by pulse oximetry $\left(\mathrm{Sp}, \mathrm{O}_{2}\right)$ and cutaneous carbon dioxide tension $\left(\mathrm{Pc}_{\mathrm{c}} \mathrm{CO}_{2}\right)$ to monitor ventilation and quantify change in $\mathrm{Pc}_{\mathrm{c}} \mathrm{CO}_{2}$ during bronchoscopy.

Combined $\mathrm{Sp}, \mathrm{O}_{2}$ and $\mathrm{Pc}_{\mathrm{c}} \mathrm{CO}_{2}$ were measured at the ear lobe in 114 patients. In four patients, the ear-clip slipped and they were excluded. In total, 11 patients had artefacts with $\mathrm{Sp}, \mathrm{O}_{2}$ recordings, thus, $\mathrm{Sp}, \mathrm{O}_{2}$ was analysed in 99 patients. Spirometry data were available in 77 patients. Multivariate analysis of covariance and logistic regression were used for statistical analyses.

Mean baseline $P c, C_{2}$ was $4.78 \pm 1.06 \mathrm{kPa}(36 \pm 8 \mathrm{mmHg})$ and mean rise in the $\mathrm{Pc}_{,} \mathrm{CO}_{2}$ during bronchoscopy was $1.26 \pm 0.70 \mathrm{kPa}(9.5 \pm 5.3 \mathrm{mmHg})$, while mean $\mathrm{Pc}_{,} \mathrm{CO}_{2}$ at the end of bronchoscopy was $5.85 \pm 1.19 \mathrm{kPa}(44 \pm 9 \mathrm{mmHg})$. Baseline $\mathrm{Pc}_{\mathrm{c}}, \mathrm{CO}_{2}$ and the lowest $\mathrm{Sp}, \mathrm{O}_{2}$ were significantly associated with peak $\mathrm{Pc}, \mathrm{CO}_{2}$ and the change in $\mathrm{Pc}_{\mathrm{c}} \mathrm{CO}_{2}$ during bronchoscopy. Risk of significant hypoxaemia $\left(\mathrm{Sp}, \mathrm{O}_{2} \leqslant 90 \%\right)$ was lower for a higher baseline $\mathrm{Sp}, \mathrm{O}_{2}$. Peak $\mathrm{Pc}_{\mathrm{c}} \mathrm{CO}_{2}$ was directly associated with significant hypoxaemia. There was no significant association in the baseline $\mathrm{Pc}, \mathrm{CO}_{2}$, peak $\mathrm{Pc}, \mathrm{CO}_{2}$, baseline $\mathrm{Sp}, \mathrm{O}_{2}$ or the lowest $\mathrm{Sp}, \mathrm{O}_{2}$ comparing patients with and without chronic obstructive pulmonary disease.

In conclusion, it is feasible to measure combined pulse oximetry and cutaneous carbon dioxide tension effectively to monitor ventilation during flexible bronchoscopy.

KEYWORDS: Bronchoscopy, cutaneous carbon dioxide tension, hypercapnia, hypoxia, oximetry

lexible bronchoscopy under local anaesthesia and sedation is widely performed to diagnose and manage a variety of lung diseases. The purpose of sedation is to facilitate examination of the tracheobronchial tree, carry out the necessary diagnostic or interventional procedures, and provide patient comfort [1-4] Oximetry measures the oxygenation of blood and can detect hypoxaemia, but it cannot detect hypercarbia and hence the adequacy of ventilation [5]. When bronchoscopy is performed under conscious sedation without supplemental oxygen, oxygen desaturation will occur rapidly giving a good indication of ventilatory status. It has recently been shown that pulse oximetry is a useful tool to assess ventilatory abnormalities, but only in the absence of supplemental inspired oxygen [6]. However, most centres routinely offer oxygen supplementation to patients during flexible bronchoscopy [7]. Due to the S-shaped curve of the oxygen dissociation curve, in such situations the alveolar carbon dioxide tension will have to increase further before significant hypoxaemia is manifested [8]. The British Thoracic Society (BTS) guidelines recommend that oxygen supplementation should be used to achieve an oxygen saturation $\left(\mathrm{Sp}, \mathrm{O}_{2}\right)$ of at least $90 \%$ to reduce the risk of significant arrhythmias during the procedure and also in the post-operative recovery period [2]. Furthermore, they suggest that care should be taken to be alert to signs of respiratory failure in patients on oxygen supplementation, who may have "safe" oximetry readings, but who may be developing carbon dioxide retention [2]. Therefore, a reliable substitute of carbon dioxide arterial tension $\left(\mathrm{Pa}, \mathrm{CO}_{2}\right)$ measured noninvasively is required as it might enhance patient safety during flexible bronchoscopy.

In intubated patients or patients under stable conditions without oral leakage, end-tidal carbon dioxide tension has a good correlation with $\mathrm{Pa}_{1} \mathrm{CO}_{2}$ [9, 10]. However, during endoscopy procedures under sedation, regular breathing is often disturbed by moving, coughing or changes between nose and mouth ventilation, causing
AFFILIATIONS

Pulmonary Medicine, University Hospital Basel, Basel, Switzerland.

CORRESPONDENCE

P.N. Chhajed

Pulmonary Medicine

University Hospital Basel

Petersgraben 4

$\mathrm{CH}-4031$

Basel

Switzerland

Fax: 41612654587

E-mail: PChhajed@uhbs.ch

Received:

July 282005

Accepted after revision:

April 102006 
leakage and artefacts or misinterpretation of the data acquired with end-tidal carbon dioxide measurements. These problems often restrict the use of side-stream capnography in clinical practice [10]. Measurement of cutaneous carbon dioxide tension $\left(P_{\mathrm{c}}, \mathrm{CO}_{2}\right)$ with a digital sensor has recently been reported [11]. The $P_{c}, \mathrm{CO}_{2}$ values have been shown to have a good correlation with arterial blood gas measurements [12, 13]. A rise in $P_{\mathrm{c}}, \mathrm{CO}_{2}$ measurement has been reported during medical thoracoscopy and colonoscopies $[10,13]$. The present authors aimed to assess the feasibility of measuring combined pulse oximetry $\left(\mathrm{Sp}, \mathrm{O}_{2}\right)$ and $\mathrm{P}_{\mathrm{c}}, \mathrm{CO}_{2}$ at the ear lobe to monitor ventilation and quantify the degree of change in $P_{\mathrm{c}, \mathrm{CO}_{2}}$ during flexible bronchoscopy under local anaesthesia and sedation.

\section{PATIENTS AND METHODS}

Combined oximetry and $P_{\mathrm{c}}, \mathrm{CO}_{2}$ were prospectively measured in 114 patients undergoing flexible bronchoscopy in an observational fashion (monitoring system from Sentec AG, Therwil, Switzerland). The combined cutaneous digital sensor was placed on the ear lobe of all patients prior to the procedure and was removed when the patient left the bronchoscopy suite.

Flexible bronchoscopy was performed under local anaesthesia and sedation. Combined sedation was achieved with intermittent boluses of intravenous midazolam and $5 \mathrm{mg}$ of hydrocodone [1]. All patients received supplemental nasal oxygen at $2-4 \mathrm{~L} \cdot \mathrm{min}^{-1}$. Significant hypoxaemia $\left(\mathrm{Sp}_{\mathrm{O}} \mathrm{O}_{2} \leqslant 90 \%\right)$ during flexible bronchoscopy was successfully treated with jaw support or nasopharyngeal tube insertion [7]. The duration of bronchoscopy was calculated from the administration of sedation until the flexible bronchoscope was removed from the tracheobronchial tree. Bronchoalveolar lavage (BAL) was performed in 57 patients, endobronchial biopsy in 32, bronchial washings in 19, transbronchial needle aspiration in 18 , transbronchial biopsy in 15 patients and bronchial brushings in 11 patients. Spirometry data prior to bronchoscopy was available in 77 patients. Patients with chronic obstructive pulmonary disease (COPD) were defined using the American Thoracic Society/European Respiratory Society guidelines [14].

\section{Statistical analysis}

Data are presented as mean \pm SD. Multivariate analysis was performed using analysis of covariance to examine peak $P_{\mathrm{c}, \mathrm{CO}_{2}}$, change in $P_{\mathrm{c}}, \mathrm{CO}_{2}$ from baseline, and change in $P_{\mathrm{c},} \mathrm{CO}_{2}$ adjusted for baseline $P_{c}, C_{2}$ during bronchoscopy as dependent factors versus patient age, dose of midazolam $\left(\mathrm{mg} \cdot \mathrm{kg}^{-1}\right)$, baseline $P_{\mathrm{c}}, \mathrm{CO}_{2}$ and lowest $\mathrm{Sp}_{\mathrm{p}} \mathrm{O}_{2}$ as independent factors. Scatterplots are provided for the association of peak $P_{\mathrm{c}, \mathrm{CO}_{2}}$ and change in $P_{c}, \mathrm{CO}_{2}$ with duration of procedure. ANOVA was used to examine the association between the type of sampling procedure during bronchoscopy with the change in $P_{c}, \mathrm{CO}_{2}$. Logistic regression was used to examine independent factors associated with significant hypoxaemia $\left(\mathrm{Sp}, \mathrm{O}_{2} \leqslant 90 \%\right)$ and COPD. The t-test was used to compare significance between the baseline and peak $P_{\mathrm{c}}, \mathrm{CO}_{2}$ during bronchoscopy and $P_{\mathrm{c}}, \mathrm{CO}_{2}$ at lowest $\mathrm{Sp}_{\mathrm{p}} \mathrm{O}_{2}$ and the peak $P_{\mathrm{c}, \mathrm{CO}_{2}}$ during bronchoscopy.

\section{RESULTS}

The mean duration of the procedure was $19 \pm 10 \mathrm{~min}$. In four patients, the ear-clip slipped off the ear lobe due to patient movement. These patients were not included in the analysis as the equilibration had to be achieved again and there was loss of data recording points. Therefore data analysis was performed in 110 patients (70 males and 40 females, mean age $61 \pm 15 \mathrm{yrs}$ ). In 11 patients, the $S_{\mathrm{p}}, \mathrm{O}_{2}$ was not included in the analysis due to artefacts produced by coughing or a low signal whilst recording. Therefore, $P_{\mathrm{c}, \mathrm{CO}_{2}}$ measurements, for the purposes of data analysis, were available in 110 patients and both oximetry and $P_{c}, \mathrm{CO}_{2}$ measurements were available in 99 patients. Therefore, for multivariate analysis only data from patients with both oximetry and $P_{c}, C_{2}$ were used. Hypoxaemia during the procedure was successfully treated with jaw support or nasopharyngeal tube insertion in all patients. None of the patients developed severe respiratory depression resulting in administration of sedation reversal medication or in abandoning the procedure without completion. The indications for bronchoscopy were: 1) suspected lung malignancy, 42 (38\%) patients; 2) radiological infiltrates, 31 $(28 \%)$ patients; 3 ) haemoptysis, nine $(8 \%)$ patients; 4$)$ suspected interstitial lung disease, nine $(8 \%)$ patients; 5) suspected sarcoidosis, five $(5 \%)$ patients; 6$)$ post-airway stent inspection, four (4\%) patients; 7) cough, three (3\%) patients; 8$)$ post-lung surgery, two ( $2 \%$ ) patients; and 9) evaluation of posttracheostomy tracheal stenosis, larngeal papilloma and mucociliary dyskinesis (all $n=1)$.

The mean dose of midazolam administered was $0.06 \pm 0.03 \mathrm{mg} \cdot \mathrm{kg}^{-1}$. The mean baseline $P_{\mathrm{c}}, \mathrm{CO}_{2}$ was $4.78 \pm 1.06$ $\mathrm{kPa}(36 \pm 8 \mathrm{mmHg})$ and the mean peak $P_{\mathrm{c}, \mathrm{CO}_{2}}$ was $6.11 \pm 1.19$ $\mathrm{kPa}(46 \pm 9 \mathrm{mmHg} ; \mathrm{p}<0.0001)$. The peak $P_{\mathrm{c}, \mathrm{CO}_{2}}$ during the procedure was recorded at a mean duration of $13 \pm 7 \mathrm{~min}$. The mean rise in the $P_{c}, \mathrm{CO}_{2}$ during the procedure was $1.26 \pm 0.70$ $\mathrm{kPa}(9.5 \pm 5.3 \mathrm{mmHg})$. The mean $P_{\mathrm{c}, \mathrm{CO}_{2}}$ at the end of the procedure was $5.85 \pm 1.19 \mathrm{kPa}(44 \pm 9 \mathrm{mmHg})$ and at the time of removal of the sensor was $5.85 \pm 1.19 \mathrm{kPa}(44 \pm 9 \mathrm{mmHg})$. A rise in $\mathrm{P}_{\mathrm{c}}, \mathrm{CO}_{2}$ was observed in all patients except one. The baseline $S_{p}, \mathrm{O}_{2}$ was $97 \pm 2 \%$. The lowest mean $S p, O_{2}$ was $93 \pm 4 \%$. The lowest $S \mathrm{p}, \mathrm{O}_{2}$ in patients who desaturated from their baseline $\mathrm{Sp}_{1} \mathrm{O}_{2}$ measurement was recorded at a mean duration of $9 \pm 6 \mathrm{~min}$. The mean $\mathrm{P}_{\mathrm{c}, \mathrm{CO}_{2}}$ measured at lowest $S \mathrm{p}, \mathrm{O}_{2}$ was $5.85 \pm 1.86 \mathrm{kPa}(44 \pm 14 \mathrm{mmHg})$ and the mean peak $P_{\mathrm{c}}, \mathrm{CO}_{2}$ recorded subsequently was $6.78 \pm 1.72 \mathrm{kPa}(51 \pm 13 \mathrm{mmHg}$; $\mathrm{p}<0.0001)$

\section{Factors associated with peak $\mathrm{Pc}, \mathrm{CO}_{2}$ and change in $\mathrm{Pc}, \mathrm{CO}_{2}$ during the study}

The peak $P_{\mathrm{c}, \mathrm{CO}_{2}}$ during the study was significantly associated with the baseline $P_{\mathrm{c}}, \mathrm{CO}_{2}(\mathrm{p}<0.0001)$ and lowest $S_{\mathrm{p}}, \mathrm{O}_{2}(\mathrm{p}=0.016)$. A higher baseline $P_{c}, C_{2}$ was associated with the peak $P_{c}, C_{2}$ $(\beta=0.8)$. However, there was an inverse relationship of the lowest $S_{p}, \mathrm{O}_{2}$ with the peak $P_{\mathrm{c}}, \mathrm{CO}_{2}$, thus, the manifestation of a lower $S_{\mathrm{p}}, \mathrm{O}_{2}$ was associated with the peak $P_{\mathrm{c}, \mathrm{CO}_{2}}(\beta=-0.4)$. Change in $P_{c}, C_{2}$ (difference in baseline and peak $P_{c}, C_{2}$ ) was also significantly associated with baseline $P_{\mathrm{c}, \mathrm{CO}_{2}}(\mathrm{p}=0.024)$ and lowest $S \mathrm{p}, \mathrm{O}_{2}(\mathrm{p}=0.016)$. Both of these factors had an inverse relationship with the change in $P_{c}, \mathrm{CO}_{2}$, thus, patients manifesting a lower $S_{\mathrm{p}}, \mathrm{O}_{2}(\beta=-0.4)$ and a lower baseline $P_{\mathrm{c}}, \mathrm{CO}_{2}$ $(\beta=-0.2)$ would have a higher change in $P_{c}, C_{2}$. Similarly, the change in $P_{c}, C_{2}$ divided by the baseline $P_{c}, C_{2}$ (adjusting the change in $P_{\mathrm{c}, \mathrm{CO}_{2}}$ for baseline) was also significantly associated with baseline $P_{\mathrm{c}, \mathrm{CO}_{2}}(\mathrm{p}<0.0001)$ and lowest $\mathrm{SO}_{2}$ 
$(\mathrm{p}=0.016)$. This analysis highlights that baseline $P_{\mathrm{c},} \mathrm{CO}_{2}$ and the lowest $\mathrm{Sp}, \mathrm{O}_{2}$ are linked to the peak $P_{\mathrm{c}}, \mathrm{CO}_{2}$ as well as the rise in $P_{\mathrm{c}, \mathrm{CO}_{2}}$ during bronchoscopy. There was no significant relationship of age and midazolam dosage with the peak $P_{\mathrm{c}}, \mathrm{CO}_{2}$, change in $P_{c}, C_{2}$ and the change in $P_{c}, C_{2} /$ baseline $P_{c}, C_{2}$. There was also no association of peak $P_{c}, C_{2}$ and change in $P_{\mathrm{c}, \mathrm{CO}_{2}}$ with the procedure duration (fig. 1). This factor was not included in the multivariate analysis as there appear to be two groups of patients; one group with higher peak $P_{c}, \mathrm{CO}_{2}$ and change in $P_{c}, C_{2}$ with a short duration of procedure and the other group of patients who have a higher peak and change in $P_{\mathrm{c}, \mathrm{CO}_{2}}$ with a longer duration of procedure. To assess the influence of procedure on change in $\mathrm{P}_{\mathrm{c}} \mathrm{CO}_{2}$ and change in $P_{\mathrm{c},} \mathrm{CO}_{2} /$ baseline $P_{\mathrm{c}}, \mathrm{CO}_{2}$, these were categorised as follows: 1) transbronchial biopsy only and transbronchial needle aspiration only $(\mathrm{n}=10) ; 2)$ BAL only $(\mathrm{n}=42) ; 3)$ transbronchial biopsy, transbronchial needle aspiration, and BAL in a combination of two or more $(n=16)$; and 4) bronchial washings and/or endobronchial biopsy $(n=42)$. There was no significant association between the procedures performed and change in $P_{\mathrm{c}, \mathrm{CO}_{2}}(\mathrm{p}=0.3)$ and change in $P_{\mathrm{c},} \mathrm{CO}_{2} /$ baseline $P_{\mathrm{c}, \mathrm{CO}_{2}}(\mathrm{p}=0.2)$ during bronchoscopy.

Factors associated with significant hypoxaemia and COPD In total, 15 patients had significant hypoxaemia during bronchoscopy. A lower baseline $\mathrm{Sp}_{\mathrm{p}} \mathrm{O}_{2}(\mathrm{p}=0.003$; odds ratio
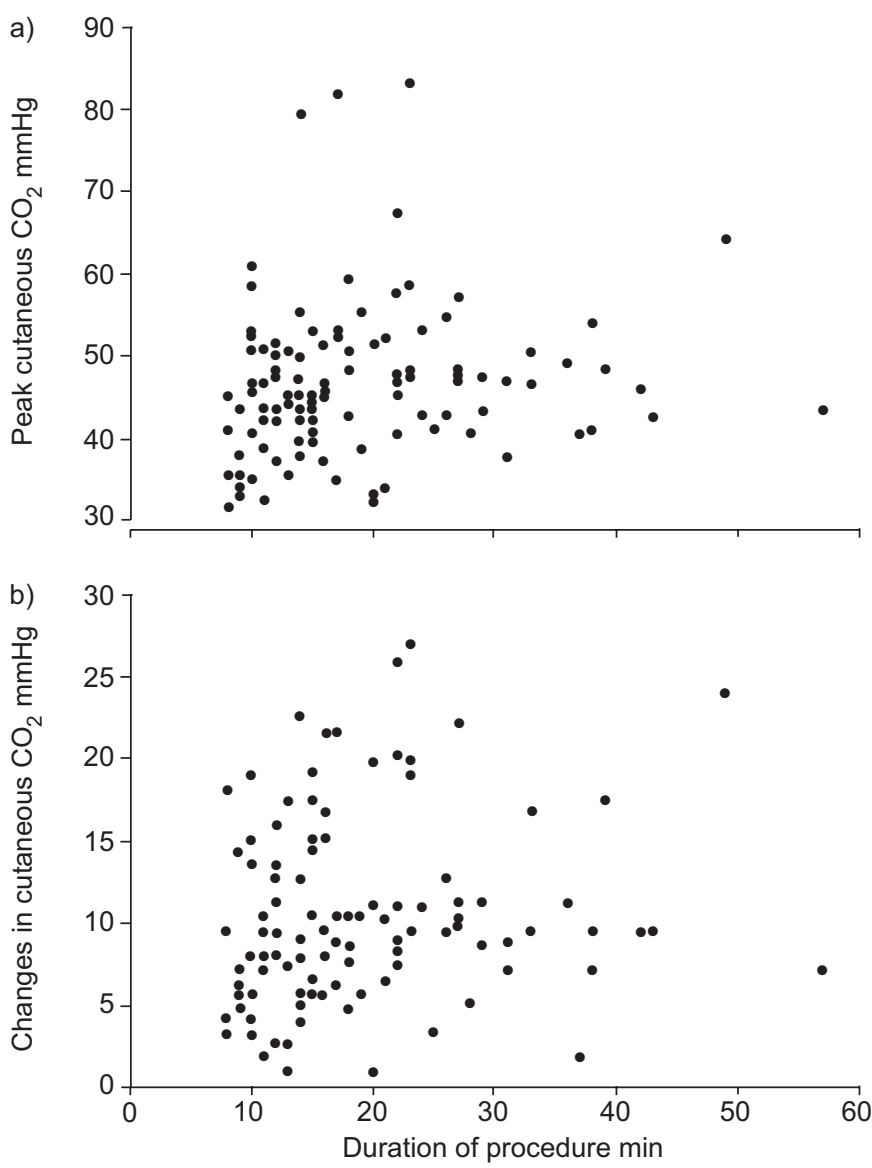

FIGURE 1. Scatter plot of duration of procedure in a) peak cutaneous carbon dioxide and b) change in cutaneous carbon dioxide.
(OR) 0.6) and the peak $P_{c, C_{2}}(p=0.041$; OR 1.1) were significantly associated with significant hypoxaemia. Therefore, with a higher baseline $\mathrm{Sp}, \mathrm{O}_{2}$ the risk of significant hypoxaemia is lower and the peak $P_{\mathrm{c}, \mathrm{CO}_{2}}$ is directly associated with significant hypoxaemia. Patient age, duration of procedure, midazolam dose and baseline $P_{\mathrm{c}}, \mathrm{CO}_{2}$ were not associated with significant hypoxaemia. In total there were 25 patients with COPD. The mean forced expiratory volume in one second in patients with mild, moderate, severe and very severe COPD was $90 \pm 10 \% \quad(n=4), 64 \pm 8 \% \quad(n=13), 39 \pm 5 \% \quad(n=6)$ and $25 \pm 3 \%(n=2)$, respectively. There was no significant association in the baseline $P_{c}, C_{2}$, peak $P_{c}, C O_{2}$, baseline $S_{p}, O_{2}$, or the lowest $\mathrm{Sp}, \mathrm{O}_{2}$ comparing patients with and without COPD.

\section{DISCUSSION}

Recently, $P_{c}, \mathrm{CO}_{2}$ measurements obtained using the device used in this study have been shown to have a good correlation with arterial carbon dioxide values when $>100$ samples were compared $(R=0.95)$ [13]. The findings of the present study show that ventilation can be effectively monitored during flexible bronchoscopy using combined oximetry and $P_{\mathrm{c}}, \mathrm{CO}_{2}$ measurement. In a study of 22 patients, an increase in $\mathrm{P}_{\mathrm{c}}, \mathrm{CO}_{2}$ has been shown to occur during flexible bronchoscopy [5]. However, EvANS et al. [5] concluded that the technology they used for $\mathrm{P}_{\mathrm{c}, \mathrm{CO}_{2}}$ monitoring was complex. Measurement of $P_{c}, \mathrm{CO}_{2}$ in the current study was simple and did not lead to a delay in the start of the procedure or any complications related to the equipment. The potential complication when using this device is burning of the skin as the sensor is heated to a temperature of $42^{\circ} \mathrm{C}$. The recommended maximum duration for which a sensor can be placed cutaneously at $42^{\circ} \mathrm{C}$ is $8 \mathrm{~h}$ [15]. None of the patients in the present study had an apparent burn on the skin. The BTS guidelines caution physicians to monitor signs of respiratory failure in patients undergoing flexible bronchoscopy on oxygen supplementation that may have safe oximetry readings, but may be developing carbon dioxide retention. Patients with a higher baseline $P_{c}, \mathrm{CO}_{2}$ are at a greater risk of developing a higher peak $P_{c}, \mathrm{CO}_{2}$. Furthermore, the peak $P_{\mathrm{c}, \mathrm{CO}_{2}}$ was significantly associated with the lowest $S_{\mathrm{p}}, \mathrm{O}_{2}$ during bronchoscopy. The results of the current study show that it is feasible to measure continuous $P_{\mathrm{c},} \mathrm{CO}_{2}$ during bronchoscopy, which has been shown to be a good surrogate of $\mathrm{Pa}_{\mathrm{a}} \mathrm{CO}_{2}[2,12$, 13]. Based on the findings of the present study, no specific trend was observed in the association between peak $P_{c}, \mathrm{CO}_{2}$ and change in $P_{c}, \mathrm{CO}_{2}$ with procedure duration, both a short and a longer procedure duration were associated with the peak $P_{c}, \mathrm{CO}_{2}$ and change in $P_{\mathrm{c}}, \mathrm{CO}_{2}$. The ability to effectively measure $P_{\mathrm{C}, \mathrm{CO}_{2}}$ is an important step in patient monitoring as diagnostic bronchoscopies are performed using routine sedation and also drugs, such as propofol, which are considered as general anaesthetics are being increasingly used also in the absence of a trained anaesthetist [16-19].

The mean duration to the manifestation of lowest $S \mathrm{p}, \mathrm{O}_{2}$ was earlier than the mean duration to the peak $P_{c}, \mathrm{CO}_{2}$. Therefore, it seems impossible to predict the occurrence of lowest $S \mathrm{p}, \mathrm{O}_{2}$ based on rising $P_{\mathrm{c}}, \mathrm{CO}_{2}$ values. The lowest $S_{\mathrm{p}}, \mathrm{O}_{2}$ manifested was significantly associated with peak $P_{c}, \mathrm{CO}_{2}$. The hypothesis for this observation is that hypoventilation during flexible bronchoscopy performed under sedation with oxygen supplementation is multifactorial, and not only due to central 
respiratory depression, in which case a rise in $P_{\mathrm{c}, \mathrm{CO}_{2}}$ would precede significant hypoxaemia due to the nature of the oxygen dissociation curve. Hypoventilation during flexible bronchoscopy is therefore due to a combination of upper airway obstruction, alveolar hypoventilation caused by sedative medication and the procedure itself [7]. The effective treatment of hypoxaemia with jaw support or nasopharyngeal tube insertion supports the role of upper airway obstruction leading to acute hypoxaemia during flexible bronchoscopy [7]. The rise in $P_{\mathrm{c}, \mathrm{CO}_{2}}$ manifested thereafter reflects alveolar hypoventilation, which is likely to be due to the combined effect of sedatives (central respiratory depression), as well as the procedure itself potentially leading to ventilation perfusion mismatch. The findings of the current study show that after effective treatment of upper airway obstruction, there continues to be a rise in $P_{c}, \mathrm{CO}_{2}$ reflecting hypoventilation. Therefore, $\mathrm{Sp}, \mathrm{O}_{2}$ alone is not sufficient to monitor the complete ventilation status of the patient during bronchoscopy, thus highlighting the value of combined oximetry and cutaneous capnography during bronchoscopy.

The permissible level of $P_{\mathrm{c}, \mathrm{CO}_{2}}$ rise during bronchoscopy is not known. The BTS guidelines state that the use of sedation in patients with severe COPD has increased risks relating to potential carbon dioxide retention [2]. The findings of the present study show that patients with COPD who are not in hypercapnic respiratory failure are at an equal risk of hypercapnia as well as hypoxaemia compared with patients without COPD. Based on the findings of the current study (mean rise in $P_{\mathrm{c}, \mathrm{CO}_{2}}$ of $1.33 \pm 0.66 \mathrm{kPa}$ ), the present authors speculate that a rise of $2.0 \mathrm{kPa}$ in $P_{\mathrm{c}}, \mathrm{CO}_{2}$ from baseline may be an indication to limit further administration of sedatives and needs to be confirmed in future studies.

In conclusion, the current study demonstrates the feasibility of measuring combined oximetry and cutaneous capnography effectively to monitor ventilation during flexible bronchoscopy. Patients with COPD who are not in hypercapnic respiratory failure have a similar risk of hypoxaemia and hypercapnia compared with those without COPD during bronchoscopy. The peak $P_{\mathrm{c}, \mathrm{CO}_{2}}$ is higher in patients with a higher baseline $P_{c}, C_{2}$ and is associated with lowest $S p, O_{2}$ during bronchoscopy. Significant hypoxaemia is associated with the peak $P_{c}, \mathrm{CO}_{2}$ and baseline $\mathrm{Sp}, \mathrm{O}_{2}$. With the current study results, it is not possible to predict and accurately select a group of patients who should undergo capnography during bronchoscopy. Patients with elevated baseline $\mathrm{Pa}_{1} \mathrm{CO}_{2}$ or a low baseline $\mathrm{Sp}_{1} \mathrm{O}_{2}$ will have the benefit of better monitoring of ventilation using such a device. Specifically, patients with a longer duration of procedure did not show a different rise in $P_{c}, \mathrm{CO}_{2}$ compared with the others. Furthermore, the current authors expected an association of the sedative dose with rise in cutaneous carbon dioxide tension, but that was also not the case. Therefore, future studies need to analyse the different patient groups with regards to the baseline cutaneous carbon dioxide tension to potentially limit the application of cutaneous capnography to only a specific group of patients.

\section{ACKNOWLEDGEMENTS}

The authors would like to thank F. Baty and A. Schötzau for their assistance with performing the statistical analysis. The authors would also like to thank Sentec AG (Therwil, Switzerland) for providing the combined cutaneous carbon dioxide and oximetry monitoring system.

\section{REFERENCES}

1 Stolz D, Chhajed PN, Leuppi JD, Brutsche M, Pflimlin E, Tamm M. Cough suppression during flexible bronchoscopy using combined sedation with midazolam and hydrocodone: a randomised, double blind, placebo controlled trial. Thorax 2004; 59: 773-776.

2 British Thoracic Society Bronchoscopy Guidelines Committee, British Thoracic Society guidelines on diagnostic flexible bronchoscopy. Thorax 2001; 56: Suppl. 1, i1-i21.

3 Ereth MH, Stubbs SE, Lennon RL. Bronchoscopic pharmacology and anesthesia. In: Prakash UBS, ed. Bronchoscopy. New York, Raven Press, 1994; p. 91.

4 Chhajed PN, Aboyoun C, Malouf MA, et al. Management of acute hypoxemia during flexible bronchoscopy with insertion of a nasopharyngeal tube in lung transplant recipients. Chest 2002; 121: 1350-1354.

5 Evans EN, Ganeshalingam K, Ebden P. Changes in oxygen saturation and transcutaneous carbon dioxide and oxygen levels in patients undergoing fibreoptic bronchoscopy. Respir Med 1998; 92: 739-742.

6 Fu ES, Downs JB, Schweiger JW, Miguel RV, Smith RA. Supplemental oxygen impairs detection of hypoventilation by pulse oximetry. Chest 2004; 126: 1552-1558.

7 Chhajed PN, Glanville AR. Management of hypoxemia during flexible bronchoscopy. Clin Chest Med 2003; 24: 511-516.

8 Chhajed PN, Heuss LT, Tamm M. Cutaneous carbon dioxide tension monitoring in adults. Curr Opin Anaesthesiol 2004; 17: 521-525.

9 Miner JR, Heegaard W, Plummer D. End-tidal carbon dioxide monitoring during procedural sedation. Acad Emerg Med 2002; 9: 275-280.

10 Heuss LT, Chhajed PN, Schnieper P, Hirt T, Beglinger C. Combined pulse oximetry/cutaneous carbon dioxide tension monitoring during colonoscopies: pilot study with a smart ear clip. Digestion 2004; 70: 152-158.

11 Kocher S, Rohling R, Tschupp A. Performance of a digital PCO2/SPO2 ear sensor. J Clin Monit 2004; 18: 75-79.

12 Chhajed PN, Langewitz W, Tamm M. (Un)explained hyperventilation. Respiration 2005: Epub ahead of print.

13 Chhajed PN, Kaegi B, Rajasekaran R, Tamm M. Detection of hypoventilation during thoracoscopy: combined cutaneous carbon dioxide tension and oximetry monitoring with a new digital sensor. Chest 2005; 127: 585-588.

14 Celli BR, MacNee W. Standards for the diagnosis and treatment of patients with COPD: a summary of the ATS/ERS position paper. Eur Respir J 2004; 23: 932-946.

15 Skin temperature at the pulse oximeter probe. In: Medical and Electrical Equipment-Particular Requirements for Basic Safety and Essential Performance of Pulse Oximeter 
Equipment for Medical Use. Geneva, International Organisation for Standardisation, 2003-2004.

16 Chhajed PN, Wallner J, Stolz D, et al. Sedative drug requirement during flexible bronchoscopy. Respiration 2005; 72: 617-621.

17 Chhajed PN, Aboyoun C, Chhajed TP, et al. Sedative drug requirements during bronchoscopy are higher in cystic fibrosis after lung transplantation. Transplantation 2005; 80: 1081-1085.
18 Heuss LT, Schnieper P, Drewe J, Pflimlin E, Beglinger C. Risk stratification and safe administration of propofol by registered nurses supervised by the gastroenterologist: a prospective observational study of more than 2000 cases. Gastrointest Endosc 2003; 57: 664-671.

19 Heuss LT, Froehlich F, Beglinger C. Changing patterns of sedation and monitoring practice during endoscopy: results of a nationwide survey in Switzerland. Endoscopy 2005; 37: 161-166. 